\title{
Improved zinc and iron absorption from breakfast meals containing malted oats with reduced phytate content
}

\author{
BY MARIE LARSSON ${ }^{1}$, LENA ROSSANDER-HULTHÉN², \\ BRITTMARIE SANDSTRÖM ${ }^{3}$ AND ANN-SOFIE SANDBERG ${ }^{1}$ \\ 'Department of Food Science, Chalmers University of Technology, S-402 29 Göteborg, Sweden \\ ${ }^{2}$ Department of Clinical Nutrition, Göteborg University, Sahlgren's Hospital, S-413 45 Göteborg, \\ Sweden \\ ${ }^{3}$ Research Department of Human Nutrition, Royal Veterinary and Agricultural University, \\ DK-1958 Fredriksberg, Denmark
}

(Received 8 August 1994 - Revised 12 February 1996-Accepted 15 March 1996)

\begin{abstract}
The absorption of $\mathrm{Zn}$ or Fe from breakfast meals containing oat porridge prepared from malted and soaked oats and a control porridge made from untreated oats was measured in human subjects. The effect on $\mathrm{Zn}$ and $\mathrm{Fe}$ absorption of reducing the phytate content of oat-porridge meals was examined in each subject by extrinsic labelling of porridge with ${ }^{65} \mathrm{Zn}$ and of bread rolls with ${ }^{55} \mathrm{Fe}$ and ${ }^{59} \mathrm{Fe}$, and measuring whole-body retention and the erythrocyte uptake of isotopes. Each experiment comprised nine to ten subjects. The absorption of $\mathrm{Zn}$ from malted-oat porridge with a phytate (inositol hexaphosphate) content of $107 \mu \mathrm{mol}$ was $18.3 \%$, and significantly higher $(P<0.05)$ than from the control porridge containing $432 \mu \mathrm{mol}$ phytate $(11.8 \%)$. Fe absorption from the meal containing malted-oat porridge with $107 \mu \mathrm{mol}$ phytate (Expt 2) was also significantly improved $(P<0.05)$ compared with that from the meal containing control porridge with $437 \mu \mathrm{mol}$ phytate. The average increase in Fe absorption was $47 \%$, or from 4.4 to $6.0 \%$. In the breakfast meal containing malted porridge with $198 \mu \mathrm{mol}$ phytate (Expt 3) the increase in Fe absorption was not significantly improved. Even though the phytate content was reduced to a greater extent in Expt 3 than Expt 2, the average increase in Fe absorption in Expt 3 was only $25 \%$ more than that from the meal containing control porridge (with $599 \mu \mathrm{mol}$ phytate), depending on the higher absolute amount of phytate. In conclusion, an improvement in $\mathrm{Zn}$ and $\mathrm{Fe}$ absorption from oat products can be achieved by practising malting and soaking in the processing of oats. This may be of importance in the prevention of mineral deficiency in vulnerable groups.
\end{abstract}

Zinc: Iron: Phytate: Oats

Oats are considered to be a nutritious cereal grain and new applications and oat products are frequently developed. However, mineral availability can be impaired at high intakes of oat products owing to the presence of high concentrations of phytate (inositol hexaphosphate; IP-6). Rossander et al. (1990) studied the inhibitory effects of oat products on non-haem-Fe absorption in human subjects from single meals and found that oat bran and oat porridge markedly inhibited $\mathrm{Fe}$ absorption. The effect on Fe stores in young, healthy subjects after dietary changes from a diet with a relatively high fat and low fibre content to a low-fat, high-fibre and high-phytate diet was investigated in a long-term study by Sandström (1993). It was found that the ferritin levels in blood were reduced during the 8-month dietary change. The absorption of $\mathrm{Zn}$ from single meals based on rye, oatmeal, barley, triticale and whole wheat was also evaluated (Sandström et al. 1987), and the lowest $\mathrm{Zn}$ absorption was observed from oatmeal porridge $(8.4 \%)$, which also contained the highest amounts of phytate. Sandström et al. (1987) concluded that when phytate-rich cereals constitute a major part of the total $\mathrm{Zn}$ intake of a diet, processes that reduce the 
phytate content could significantly improve the absorption of $\mathrm{Zn}$. The high content of phytate combined with a low phytase $(E C 3.1 .3 .26)$ activity and heat inactivation during treatment of all commercial oat products suggests that mineral absorption from oat products is less than that from other cereals.

We recently reported (Larsson \& Sandberg, 1992) that it is possible to reduce the phytate content in oats to low levels by malting and soaking under optimal conditions. The aim of the present study was to confirm that malting of oats, resulting in a lower phytate content, improves $\mathrm{Zn}$ and $\mathrm{Fe}$ absorption.

\section{MATERIALS AND METHODS}

Oats were malted in a pilot-plant process or in the laboratory according to methods previously described (Larsson \& Sandberg, 1992). Malting in the pilot plant was performed at Svenska Cereallaboratoriet AB, Sweden. Oats were dehulled by an industrial process (Kungsörnen AB, Järna, Sweden) and steeped for $6.5 \mathrm{~h}$ at $25^{\circ}$. Germination was performed at $15^{\circ}$ in rotating chests in which the temperature and moisture content were controlled precisely. To maintain adequate grain moisture during germination, air, which had been humidified ( $90 \%$ relative humidity), was passed through the chests. The oats were allowed to germinate for $120 \mathrm{~h}$ and were subsequently dried at $30^{\circ}$ for $18 \mathrm{~h}$. The material was further heat-treated in a step-wise process from 30 to $80^{\circ}$ according to the following schedule: $2 \mathrm{~h}$ at $40^{\circ}, 2 \mathrm{~h}$ at $50^{\circ}, 8 \mathrm{~h}$ at $65^{\circ}$ and $10 \mathrm{~h}$ at $80^{\circ}$. Malting in the laboratory was performed using a laboratory incubator (Memmert Model BKE 30; Memmert GmbH, Schwabach, Germany). Oats were dehulled with a laboratory dehuller (Nygård kvarn, Vargön, Sweden) and steeped for $7 \mathrm{~h}$ at $25^{\circ}$. The steeped oats were spread in single layers on trays and dried at $30^{\circ}$ for $1 \mathrm{~h}$ in order to achieve the correct moisture conditions during germination. During the germination period the oats were moistened with water two to three times during the day. The incubator was held at $15^{\circ}$ and the oats were germinated for $5 \mathrm{~d}$, and subsequently dried overnight at $30^{\circ}$.

\section{Expt 1. Zinc absorption}

Preparation of malted-oat porridge. Oats malted in the pilot plant (dried at $80^{\circ}$ ) were ground to a flour in a coffee mill (Model Kenwood CG 100; Kenwood Ltd, Havant, Hants) before soaking. Samples of malted-oat flour ( $30 \mathrm{~g}$ portions of test meal) were suspended in $150 \mathrm{ml}$ distilled water in plastic beakers and soaked first for $17 \mathrm{~h}$ at room temperature $\left(23^{\circ}\right)$ and then for $8 \mathrm{~h}$ at $37.8^{\circ}$. After soaking, the samples were kept at $4^{\circ}$ overnight. The samples were frozen the following day and kept at $-20^{\circ}$ until used. Immediately before serving, samples were thawed at low power in a microwave oven. Each portion was prepared by cooking in a microwave oven for $2 \mathrm{~min}$.

Experimental design. Zn absorption was determined using the radionuclide technique described by Arvidsson et al. (1978). Each individual meal was extrinsically labelled by the addition of $0.02 \mathrm{MBq}^{65} \mathrm{ZnCl}_{2}$ (Amersham International, Amersham, Bucks.) and the activity of each porridge was measured in the whole-body counter before serving. Each subject's background was also measured in the whole-body counter before intake of the labelled test meal. The meals were served as breakfast. No food or drink was allowed during the $12 \mathrm{~h}$ period before breakfast or $3 \mathrm{~h}$ after intake of the test meal. The whole-body retention was measured once, 10-14 d after intake of the meal to allow excretion of the unabsorbed fraction. Allowance was made for the excretion of the initially absorbed isotope during the time between intake and retention measurement, based on the mean rate of excretion of an intravenously-administered dose of ${ }^{65} \mathrm{Zn}$ in a similar group of subjects (Arvidsson et al. 1978). Each subject participated twice, and the sequence of serving the malted porridge and control porridge to the subjects was randomized. Allowance was also 
made on the second occasion for residual activity from the first meal. During the first $10 \mathrm{~d}$, 11 (SD 0.3 ) \% of the absorbed dose was excreted, and the mean excretion from day 10 to day 30 was $10 \%$. The CV due to counting statistics of a typical retention value from the administered dose was $1.5 \%$.

The meals consisted of porridge prepared from the suspension described previously: $30 \mathrm{~g}$ malted-oat flour (test meal) or $30 \mathrm{~g}$ untreated (control meal), dehulled and ground oats (from the same batch as the malted oats). The porridge was prepared by adding $1 \mathrm{~g}$ table salt and cooking in a microwave oven for $2 \mathrm{~min}$. The isotope was added to the porridge after heating. The porridge was served without any addition of milk or jam.

Subjects. Seven females and three males between 21 and 30 years of age volunteered to take part in the study. All ten subjects participated twice. They were all apparently healthy, not pregnant and with no known gastrointestinal disorders, and had normal serum $\mathrm{Zn}$ levels of 9.3-12.2 (mean 11.0) $\mu \mathrm{mol} / 1$. The subjects were given written and oral information about the aim and procedure of the study and the project was approved by the Ethics Committee and the Isotope Committee at Sahlgren's Hospital.

\section{Expts 2 and 3. Iron absorption}

Fe absorption was measured in two experiments with malted-oat porridge prepared in different ways and at two levels of phytate.

Preparation of malted-oat porridge. In Expt 2, oats malted in the pilot plant (dried at $80^{\circ}$ ) were ground to a flour in a coffee mill before soaking. Samples of malted-oat flour $(30 \mathrm{~g})$ were suspended in $300 \mathrm{ml}$ distilled water in plastic beakers and soaked first for $16 \mathrm{~h}$ at room temperature and then for $7 \mathrm{~h}$ at $37.8^{\circ}$.

After soaking, $175 \mathrm{ml}$ of the supernatant fraction was removed from each sample to reduce the volume of the fluid and, thus, achieve an acceptable consistency of the porridge, and the remaining $125 \mathrm{ml}$ was transferred to a plastic jar. The beaker was rinsed with $25 \mathrm{ml}$ of the supernatant fraction and this volume was added back to the oat-flour slurry, resulting in a sample volume of $150 \mathrm{ml}$, which was kept in the refrigerator $\left(+4^{\circ}\right)$ overnight. On the following day each portion of test porridge was prepared by cooking the sample in a microwave oven for $2 \mathrm{~min}$.

The control porridge portion was prepared by mixing $150 \mathrm{ml}$ distilled water with $30 \mathrm{~g}$ untreated, dehulled and ground oats (from the same batch as the malted oats) and $2 \mathrm{~g}$ salt, and then cooking in a microwave oven for $2 \mathrm{~min}$.

In Expt 3, oats malted in the laboratory were dried at $30^{\circ}$ and ground to a flour. Samples of malted-oat flour ( $32 \mathrm{~g}$ ) were suspended in $150 \mathrm{ml}$ distilled water and soaked for $9 \mathrm{~h}$ at $38^{\circ}$. After soaking, the samples were kept in the refrigerator overnight. On the following day each portion of test porridge was prepared by cooking the sample with $2 \mathrm{~g}$ salt in a microwave oven for $2 \mathrm{~min}$. The control porridge was prepared by mixing $150 \mathrm{ml}$ distilled water with $36 \mathrm{~g}$ untreated, dehulled and ground oats and $2 \mathrm{~g}$ salt, and then cooking in a microwave oven for $2 \mathrm{~min}$. Untreated oats have a higher moisture content than oats that have been malted and dried at $80^{\circ}$ and, therefore, different amounts of ground oats were used for the preparation of oat porridge.

Experimental design. Fe absorption was determined using the method described by Eakins \& Brown (1966) with the exception that $5 \mathrm{mg}$ radio- $\mathrm{Fe}$ is used instead of $10 \mathrm{mg}$ in order to keep the administered dose of radioactivity at a lower level. The principle and basic requirements for the determination of non-haem-Fe absorption, including radioisotope measurements, calculation of absorption and sources of error in measurements of food $\mathrm{Fe}$ absorption, have been described previously (Hallberg, 1980).

The different portions of test porridge and control porridge ( $\mathrm{A}$ and $\mathrm{B}$ ) were served in breakfast meals on alternate mornings after overnight fasting, on four consecutive days 
in the order ABBA or BAAB. Each control or test meal consisted of one wheat roll labelled with two different radio-Fe isotopes, ${ }^{55} \mathrm{Fe}$ and ${ }^{59} \mathrm{Fe}$. At 2 weeks after the final breakfast a blood sample was withdrawn to determine the content of ${ }^{55} \mathrm{Fe}$ and ${ }^{59} \mathrm{Fe}$. The total retention of ${ }^{59} \mathrm{Fe}$ was measured by whole-body counting at the same time and the total retention of ${ }^{55} \mathrm{Fe}$ was calculated from ${ }^{55} \mathrm{Fe}:{ }^{59} \mathrm{Fe}$ in erythrocytes. One oral reference dose of $\mathrm{FeSO}_{4}$ was then given to the fasting subject as well as a second dose on the following morning. The absorption of the reference dose was then measured by whole-body counter 2 weeks later.

Oral reference dose. A solution of $10 \mathrm{ml} 0.01 \mathrm{~mol} \mathrm{HCl} / 1$ containing $3 \mathrm{mg} \mathrm{Fe}$ as $\mathrm{FeSO}_{4}$ and $30 \mathrm{mg}$ ascorbic acid labelled with ${ }^{55} \mathrm{Fe}$ was used as a reference in all subjects. The $10 \mathrm{ml}$ vial containing the Fe solution was rinsed twice with water and this was also consumed. Each subject received two reference doses on two consecutive mornings after overnight fasts. No food or drink was allowed for $3 \mathrm{~h}$ after the reference dose. Each subject received a total of $55 \cdot 5 \mathrm{kBq}{ }^{55} \mathrm{Fe}$.

Bread making. The rolls were baked from $40 \mathrm{~g}$ unfortified white wheat flour of $55 \%$ extraction, table salt, yeast, sugar and water. The native $\mathrm{Fe}$ content of the flour was $0.2 \mathrm{mg} / 40 \mathrm{~g}$ flour. $\mathrm{FeSO}_{4}$ was added in an amount corresponding to $1.9 \mathrm{mg} \mathrm{Fe} / 40 \mathrm{~g}$ flour. The dough was fermented for $1 \mathrm{~h}$ at $23^{\circ}$. It was then kneaded, and weighed amounts were transferred to small $\mathrm{Al}$ forms which were left standing for $10 \mathrm{~min}$ of further fermentation. The rolls were then baked at $250^{\circ}$ for $15 \mathrm{~min}$. During the mixing of the dough the rolls were labelled with two different radio-Fe isotopes $\left({ }^{55} \mathrm{Fe}\right.$ and $\left.{ }^{59} \mathrm{Fe}\right)$; each roll was labelled with $0.02 \mathrm{MBq}(0.5 \mu \mathrm{Ci}){ }^{55} \mathrm{Fe}$ or $0.03 \mathrm{MBq}(0.75 \mu \mathrm{Ci}){ }^{59} \mathrm{Fe}$. The radio-Fe was added as highspecific-activity $\mathrm{FeCl}_{3}$ in $\mathbf{0 . 0 1} \mathrm{M}-\mathrm{HCl}$. Several studies have shown that it is possible to label uniformly almost all non-haem-Fe compounds in a meal by using this method (Cook et al. 1972; Hallberg \& Björn-Rasmussen, 1972).

Subjects. Eighteen subjects, six men and twelve women, participated in the experiments. All subjects were healthy volunteers, aged 19-47 years, and each group of nine subjects included three men and six women. Some of the subjects in each group were regular blood donors, which provided a reasonable range of inter-subject variation in Fe absorption. All subjects had normal haemoglobin levels of 130-157 (mean 141) g/l. The volunteers were given oral and written information about the aims and procedures of the study. The project was approved by the Ethics Committee and the Isotope Committee at Sahlgren's Hospital.

Meal composition. Each control or test meal consisted of one wheat roll prepared as described previously. The rolls were divided into two halves and served with margarine $(6 \mathrm{~g}$ per half) and orange marmalade $(5 \mathrm{~g}$ per half). Coffee $(150 \mathrm{ml})$ was served with the meal. The test and control porridges were made according to the preparation of porridge (Expts 1 and 2) described previously. They were boiled with $2 \mathrm{~g}$ table salt and served without milk. Orange juice $(150 \mathrm{ml})$ was served with all meals and was prepared from a frozen concentrate, reconstituted with water. The ascorbic acid content of the meal was $70 \mathrm{mg}$ and the total Fe content was between 3.4 and $3.6 \mathrm{mg}$.

Iron absorption measurements. The relative absorption of ${ }^{55} \mathrm{Fe}$ and ${ }^{59} \mathrm{Fe}$ was calculated from analyses of blood samples. The absolute absorption of the two tracers was calculated from a whole-body count of ${ }^{59} \mathrm{Fe}$ and the relative absorption of the two tracers. The analyses of ${ }^{55} \mathrm{Fe}$ and ${ }^{59} \mathrm{Fe}$ in blood was made by means of the method described by Eakins \& Brown (1966). All procedures and calculations have been described previously (BjörnRasmussen et al. 1974; Hallberg, 1980).

Expressing results of iron absorption measurements. By measuring absorption of ${ }^{55} \mathrm{Fe}$ in each subject both from the meals and from the reference dose, the results can be expressed as a regression line between the two absorption measurements. A difference in Fe absorption between two meals can then be assessed by comparing the slopes of the regression lines relating meal $\mathrm{Fe}$ absorption to absorption of the reference dose. Earlier studies indicated that such regression lines are linear and that it is reasonable to assume that the regression 
line passes through the origin (Magnusson et al. 1981). This implies that the ratio of mean absorption from a meal to that from the reference dose is a measure of relative bioavailability of non-haem-Fe in the meal. To describe Fe absorption from a given meal, an expression is needed that is more concrete and absolute than the absorption ratio between the meal and reference dose. It is more meaningful to state the amount of $\mathrm{Fe}$ absorbed from meals at a specific absorption of the reference dose. In Fe balance considerations it is important to know the Fe absorption from various meals in subjects who are borderline deficient, that is subjects with absent $F e$ stores who have yet not developed anaemia. The absorption of the reference dose in such subjects has been assessed to be about $40 \%$. Mean, median values and standard deviations of absorption values corresponding to a reference dose absorption of $40 \%$ can thus be calculated from groups of subjects.

\section{Analytical methods}

Duplicate samples $(2.0 \mathrm{~g})$ of freeze-dried porridge were analysed for their contents of $\mathrm{Fe}$ and $\mathrm{Zn}$. All glassware was washed in $2.5 \mathrm{M}-\mathrm{HCl}$ and rinsed in deionized water before use. $\mathrm{Fe}$ and $\mathrm{Zn}$ were determined by atomic absorption spectrophotometry (Perkin Elmer Model 360 ; Perkin Elmer Co., Norwalk, CT, USA) after dry-ashing at $450^{\circ}$. After cooling, three drops $\mathrm{HNO}_{3}(430 \mathrm{ml} / \mathrm{l})$ were added, the ashing was continued, a further three drops $\mathrm{HNO}_{3}$ were added and the ashing then continued until a white or yellow residue remained. The ash was dissolved in $5 \mathrm{ml} 5 \mathrm{M}-\mathrm{HCl}$ and allowed to stand under cover overnight. The solutions were transferred with demineralized water to $25 \mathrm{ml}$ volumetric flasks, made up to volume and left for at least $4 \mathrm{~h}$ before analysis. Reference standards for $\mathrm{Zn}$ and Fe were prepared from Titrisol (Merck, Darmstadt, Germany). Reference standard materials for $\mathrm{Zn}$ and $\mathrm{Fe}$ with concentrations representative of those found in the test meals were run simultaneously and were seen to fall within the certified range (Orchard Leaves SRM 1571 and Bovine Liver SRM 1577 (a), National Bureau of Standards, USA). The CV for control materials of $\mathrm{Zn}$ and $\mathrm{Fe}$ were $3 \cdot 1$ and $4.4 \%$ respectively.

Analysis of phytate and its degradation products was carried out on untreated oats, control porridge and test porridge. Duplicate samples of freeze-dried material $(0.5 \mathrm{~g})$ were extracted with $20 \mathrm{ml} 0.5 \mathrm{M}-\mathrm{HCl}$ for $3 \mathrm{~h}$. The inositol phosphates were separated from the crude extract by ion-exchange chromatography and determined by ion-pair $\mathrm{C}_{18}$ reversephase HPLC using formic acid-methanol (Merck) and tetrabutyl-ammonium hydroxide (Fluka Chemie AG, Buchs, Switzerland) in the mobile phase. The mobile phase was prepared by mixing $560 \mathrm{ml}$ methanol with $540 \mathrm{ml} \mathrm{0.05} \mathrm{M-formic} \mathrm{acid} \mathrm{in} \mathrm{water.} \mathrm{Tetrabutyl-}$ ammonium hydroxide $(15 \mathrm{ml})$ was added. The amounts of inositol phosphates (tri(IP-3)-, tetra(IP-4)-, penta(IP-5)- and hexa(IP-6)-) were determined by HPLC, according to Sandberg \& Adherinne (1986) and Sandberg et al. (1989). The analysis was performed using a HPLC pump (Waters model 510; Waters Associates, Milford, MA, USA) equipped with a $\mathrm{C}_{18}$ Chromasil (pore size $\left.5 \mu \mathrm{m}\right)$ column $(150 \mathrm{~mm}, 2 \mathrm{~mm}$ i.d.). The inositol phosphates were detected by refractive index (ERC-7510 RI-detector; Erma Optical Works Ltd, Tokyo, Japan). Retention times and peak areas were measured using a Hewlett Packard analytical data system (HP 3350; Hewlett Packard, Palo Alto, CA, USA). Injections were made with a Poole $20 \mu 1$ loop. The precision of the HPLC method was tested by repeating the extraction and analysis of the same batch of wheat bran in twelve replicate samples. The mean of wheat-bran samples was 46.9 (SD 1.5) $\mu \mathrm{mol} / \mathrm{g}$ (dry basis). The same procedure was applied to four samples of rye (wholemeal flour) and four samples of phytase-deactivated oats (wholemeal flour). Mean values were $10 \cdot 3$ (SD 0.2) and 9.9 (sD 0.35) $\mu \mathrm{mol}$ inositol hexaphosphates/g (dry basis) respectively. The precision of the HPLC method was estimated from these results to be about $\pm 3 \%(\mathrm{CV})$.

The phytate content of the porridge in the present study was expressed as $\mu$ mol inositol 
Table 1. Expt 1. Zinc absorption from oat porridge by healthy human subjects

(Mean values and standard deviations)

\begin{tabular}{|c|c|c|c|c|c|c|c|c|}
\hline \multirow[b]{2}{*}{ Meal } & \multirow[b]{2}{*}{$n$} & \multicolumn{2}{|c|}{$\mathrm{Zn}$ content } & \multicolumn{2}{|c|}{$\mathrm{Zn}$ absorption (\%) } & \multicolumn{2}{|c|}{$\begin{array}{l}\text { Absorption ratio } \\
\text { test: control }\end{array}$} & \multirow{2}{*}{$\begin{array}{c}\text { Inositol } \\
\text { hexaphosphate } \\
\text { ( } \mu \mathrm{mol} / \text { portion }\end{array}$} \\
\hline & & $\mathrm{mg} / \mathrm{kg}$ & $\mu \mathrm{mol} /$ portion & Mean & SD & Mean & SD & \\
\hline Control & 10 & $35 \cdot 6$ & $14 \cdot 5$ & $11 \cdot 8^{\mathrm{a}}$ & $2 \cdot 96$ & \multirow{2}{*}{1.63} & \multirow{2}{*}{0.75} & 432 \\
\hline Test & 10 & $30 \cdot 8$ & 13.6 & $18 \cdot 3^{b}$ & $8 \cdot 12$ & & & 107 \\
\hline
\end{tabular}

a, b Mean values with unlike superscript letters were significantly different $(P<0.05)$.

* For details of subjects and experimental procedures, see pp. 678-681.

hexaphosphate. For comparison of our results with previous studies, where phytate content was expressed as $\mathrm{mg}$, we converted the inositol phosphate contents expressed as $\mathrm{mg}$ to $\mu \mathrm{mol}$. The following molecular weights (P) were used for this conversion: IP-3 $93 \mathrm{~g} / \mathrm{mol}$, IP-4 $124 \mathrm{~g} / \mathrm{mol}$, IP-5 $155 \mathrm{~g} / \mathrm{mol}$ and IP-6 $186 \mathrm{~g} / \mathrm{mol}$. In two of the studies used for comparison (Hallberg et al. 1989; Rossander et al. 1990) this was not possible since the separate inositol fractions were not analysed in these studies. The conversion of these values from $\mathrm{mg}$ to $\mu \mathrm{mol}$ was made by multiplying $\mathrm{mg}$ by the molecular weight of IP-6, these values therefore, should be regarded as estimates of the phytate content given in $\mu \mathrm{mol}$.

\section{Phytate hydrolysis}

Phytate hydrolysis in untreated oat flour after cooking in the microwave oven for 2 min was determined by analysis of phytate content before and after soaking at $37.8^{\circ}$ for $17 \mathrm{~h}$ and was compared with phytate hydrolysis in untreated oat flour, soaked without cooking. After soaking, the samples were freeze-dried before analysis of phytate (IP-6).

\section{Statistical analysis}

The significance of the differences between the absorption of the isotopes in each study was calculated by use of Student's $t$ test for paired observations.

\section{RESULTS \\ Zinc absorption}

Zinc absorption measurements. The $\mathrm{Zn}$ and phytate contents of the different porridge meals and the absorption of $\mathrm{Zn}$ are given in Table 1 . The $\mathrm{Zn}$ absorption from the control porridge prepared from untreated oats, with a phytate (inositol hexaphosphate) content of $432 \mu \mathrm{mol}$, was $11.8 \%$. The serving of the malted-oat porridge with a phytate content of $107 \mu \mathrm{mol}$ enhanced $\mathrm{Zn}$ absorption significantly $(P<0.05)$, to $18.3 \%$.

\section{Iron absorption}

Iron absorption measurements. The Fe absorption from different breakfast meals is shown in Table 2. In Expt 2 the phytate content in the test porridge was $107 \mu \mathrm{mol}$ and in the control porridge $437 \mu \mathrm{mol}$. The mean individual absorption ratio (test porridge meal: control porridge meal) was $1.47(P<0.05)$. In Expt 3 a tendency towards a higher absorption from the malted-porridge meal than from the control-porridge meal was observed which did not, however, reach statistical significance. The mean of the ratios calculated from the different individual Fe absorptions in this experiment was 1.25.

Phytate analysis. The inositol phosphate contents of the meals served in the $\mathrm{Zn}$ and $\mathrm{Fe}$ 


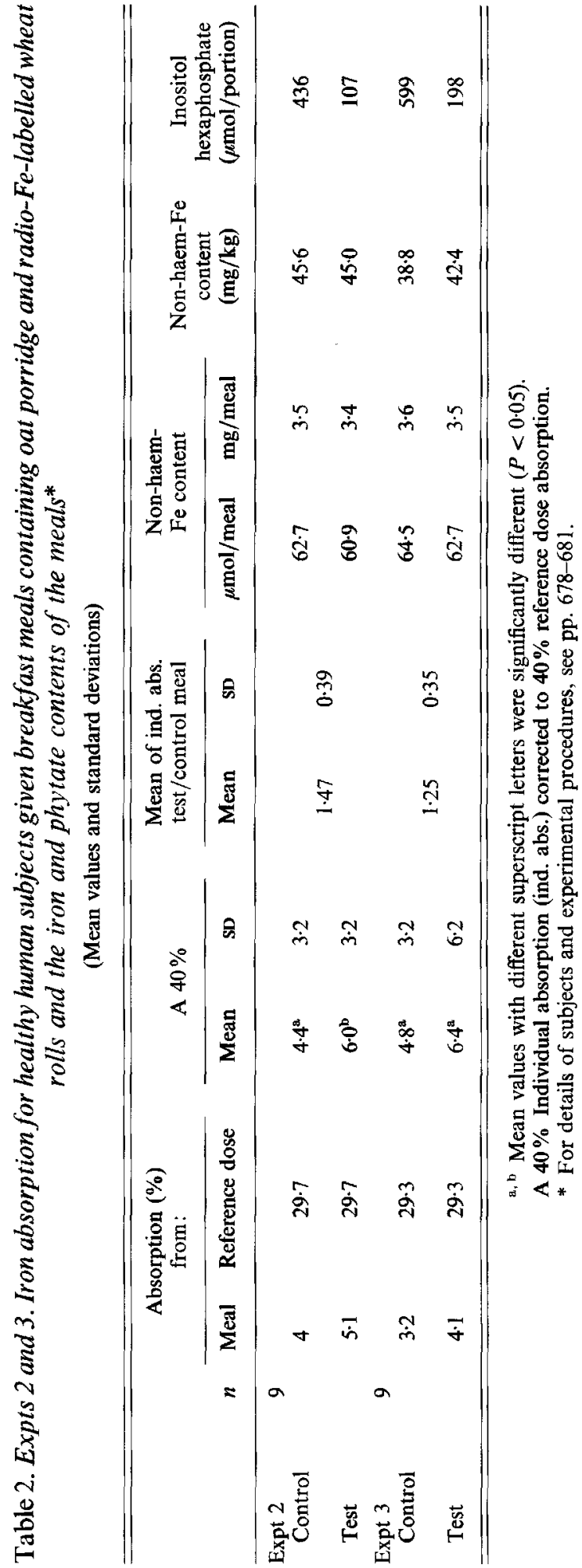


Table 3. Content of inositol phosphates $(\mu \mathrm{mol} / \mathrm{g}$ ) in breakfast meals containing different oat porridge preparations*

(Mean values with two values from duplicate determinations shown in parentheses)

\begin{tabular}{|c|c|c|c|c|c|}
\hline Samples & $\begin{array}{l}\text { IP-3 } \\
\text { Mean }\end{array}$ & $\begin{array}{c}\text { IP-4 } \\
\text { Mean }\end{array}$ & $\begin{array}{c}\text { IP-5 } \\
\text { Mean }\end{array}$ & $\begin{array}{c}\text { IP-6 } \\
\text { Mean }\end{array}$ & $\begin{array}{l}\text { Sum of } \\
\text { IP-3-IP-6 } \\
(\mu \mathrm{mol} \\
\text { /portion })\end{array}$ \\
\hline \multicolumn{6}{|l|}{ Expt 1} \\
\hline $\begin{array}{l}\text { Control } \\
\text { porridge }\end{array}$ & - & - & $0.6(0.62,0.57)$ & $16 \cdot 2(16 \cdot 44,15 \cdot 96)$ & 448 \\
\hline $\begin{array}{l}\text { Test } \\
\text { porridge }\end{array}$ & $1.0(0.97,1.02)$ & $1.6(1.72,1.47)$ & $1 \cdot 4(1 \cdot 48,1 \cdot 32)$ & $3 \cdot 7(4 \cdot 47,2 \cdot 93)$ & 222 \\
\hline \multicolumn{6}{|l|}{ Expt 2} \\
\hline & - & - & $0.6(0.55,0.64)$ & $14 \cdot 5(14 \cdot 88,14 \cdot 12)$ & 452 \\
\hline $\begin{array}{l}\text { Test } \\
\text { porridge }\end{array}$ & $1 \cdot 1(1 \cdot 02,1 \cdot 18)$ & $1 \cdot 7(1 \cdot 64,1 \cdot 76)$ & $1.5(1.50,1 \cdot 50)$ & $3 \cdot 7(3 \cdot 85,3 \cdot 55)$ & 231 \\
\hline \multicolumn{6}{|l|}{ Expt 3} \\
\hline $\begin{array}{l}\text { Control } \\
\text { porridge }\end{array}$ & - & - & $0.6(0.55,0.64)$ & $16 \cdot 6(16 \cdot 22,15 \cdot 98)$ & 621 \\
\hline $\begin{array}{l}\text { Test } \\
\text { porridge }\end{array}$ & $2 \cdot 6(2 \cdot 56,2 \cdot 73)$ & $2 \cdot 8(2 \cdot 82,2 \cdot 78)$ & $2 \cdot 3(2 \cdot 31,2 \cdot 29)$ & $6.0(6.06,5.94)$ & 452 \\
\hline
\end{tabular}

IP-3, IP-4, IP-5, IP-6, inositol tri-, tetra-, penta- and hexaphosphates respectively.

* For details of experimental procedures, see p. 681 .

absorption experiments are shown in Table 3. In the $\mathrm{Zn}$ absorption experiment (Expt 1 ) the sum of IP-3, IP-4, IP-5 and IP-6 in the control and the test porridge was found to be similar to the values from determinations of the porridge served in Expt 2 (Fe absorption). In Expt 3 (Table 2) the phytate content was higher; the control porridge contained $599 \mu \mathrm{mol}$ per portion and the test porridge $198 \mu \mathrm{mol}$ per portion.

Phytate hydrolysis in oat samples after cooking in the microwave oven. The IP-6 content of untreated, dehulled and ground oats was reduced by $65 \%$ from 16.2 to $5.8 \mu \mathrm{mol} / \mathrm{g}$ $(3 \cdot 0-1 \cdot 1 \mathrm{mg})$ during soaking at $37.8^{\circ}$ for $17 \mathrm{~h}$. When the soaking was repeated with ground oats, cooked in the microwave oven for $2 \mathrm{~min}$, only a small reduction was observed $(8 \%)$, and there was less formation of hydrolysis products of phytate.

\section{DISCUSSION}

In the present study, malting and soaking of oats reduced the phytate (IP-6) content by $77 \%$ and doubled the amount of $\mathrm{Zn}$ absorbed, as compared with oat porridge prepared from untreated oats. The average individual increase in Fe absorption was $47 \%$ from oat porridge with $107 \mu \mathrm{mol}$ phytate (Expt 2).

The absorption of $\mathrm{Zn}$ and $\mathrm{Fe}$ in the present study was estimated from measurements of the whole-body retention from radio-labelled meals. $\mathrm{Zn}$ absorption was measured by adding radio- $\mathrm{Zn}$ to porridge, and $\mathrm{Fe}$ absorption was measured by giving porridge with a bread roll containing the radio-Fe. The reason for this was to achieve a similar experimental design to that used in previous studies (Sandström et al. 1987; Rossander et al. 1990; Brune et al. 1992), and thereby facilitate comparison of the observations in our study with previous results. Extrinsic labelling of meals or diets with radioactive isotopes, followed by measurement of whole-body retention or enrichment in, for example, blood, has been 
shown to give a valid and precise determination of the absorption of $\mathrm{Zn}$ and $\mathrm{Fe}$ for a range of foods (Hallberg \& Björn-Rasmussen, 1972; Arvidsson et al. 1978). These previous studies found that, with few exceptions, a complete and rapid isotopic exchange occurs in a majority of foods items. Thus, the absorption of radio tracers can be expected to be the same from the porridge and the bread roll.

Several studies of cereal-based meals have confirmed the negative effect of phytate on $\mathrm{Zn}$ absorption in human subjects (Turnlund et al. 1984; Sandström et al. 1987; Kivistö et al. 1989).

When data obtained in these studies are evaluated together, low absorption values, less than $15 \%$, are consistently observed when the phytate content of the test meal is above $400 \mu \mathrm{mol}$.

Nävert et al. (1985) studied $\mathrm{Zn}$ absorption from bread meals containing wheat bran fermented for varying lengths of time. The absorption of $\mathrm{Zn}$ increased from $9 \cdot 6 \%$ to $19 \cdot 8 \%$ when the phytate content (sum of IP-3 to IP-6) was reduced from $520 \mu \mathrm{mol}$ (97 mg phytateP) to $230 \mu \mathrm{mol}$ ( $26 \mathrm{mg}$ phytate-P) by $16 \mathrm{~h}$ of fermentation, thus suggesting that the $\mathrm{Zn}$ absorption was improved by the fermentation process. These values are almost identical to our observations. The breads in the study by Nävert et al. (1985) were not analysed by HPLC but by the earlier precipitation techniques that do not separate the different inositol phosphates. Since the values obtained with the Fe precipitation methods may result in overestimation of phytate, Sandström \& Sandberg (1992), in a recent study, re-analysed the freeze-dried samples studied by Nävert et al. (1985), using the HPLC method described previously, and these data have been used for comparison with the results from our study. In another study, Sandström et al. (1987) measured $\mathrm{Zn}$ absorption from cereals prepared in the form of bread or porridge and served with $200 \mathrm{ml}$ milk. The absorption of Zn was negatively correlated with the phytate content of the meal with the highest absorption, $26.8 \%$, from a rye bread containing $126 \mu \mathrm{mol}$, calculated as the sum of IP-3 to IP-6 ( $21 \mathrm{mg}$ phytate-P) and the lowest, $8.4 \%$, from an oatmeal porridge containing $426 \mu \mathrm{mol}(75 \mathrm{mg}$ phytate-P), and these values are similar to the values from the studies discussed previously. However, direct comparison is not possible, as the studies of Sandström et al. (1987) contained different amounts of $\mathrm{Zn}$ and were served with milk, which may have influenced the results.

Both human (Sandström \& Sandberg, 1992) and animal studies (Lönnerdal et al. 1989) have indicated that inositol phosphates containing less than five phosphate groups may induce lower inhibition of mineral absorption than IP-5 and IP-6. Studies with sucking rats suggest that pure fractions of inositol phosphates containing less than five phosphate groups produced via non-enzymic hydrolysis have no effect on $\mathrm{Zn}$ absorption (Lönnerdal et al. 1989). In a recent study (Sandström \& Sandberg, 1992) the inhibitory effects of isolated inositol phosphates on $\mathrm{Zn}$ absorption in human subjects was investigated. $\mathrm{Zn}$ absorption was impaired when pure fractions of IP-5 and IP- 6 produced by non-enzymic hydrolysis were added to a white bread, while the addition of $400 \mu \mathrm{mol} \mathrm{IP}-4$ had no effect. In the present study, malting and soaking resulted in phytate hydrolysis and, as shown in Table 3, IP-3 and IP-4 constituted a considerable fraction of the total inosital phosphates in malted-oat porridge. In the $\mathrm{Zn}$ experiment, $13 \%$ of the inositol phosphates comprised IP-3, $21 \%$ IP-4, $18 \%$ IP-5, and $48 \%$ IP-6.

However, when phytate is hydrolysed, different isomers of inositol phosphates can be produced depending on whether the hydrolysis is non-enzymic or enzymic, and whether cereal or microbial phytases are used. As it is possible that the configuration of the phosphate groups may affect the complexing capacity of the molecule, direct comparisons between the present and previous studies such as Lönnerdal et al. (1989) and Sandström \& Sandberg (1992) are difficult. 
In the present study the Fe absorption from the bread rolls served with the porridge made from malted-oat flour was higher than the absorption from that served with the control porridge prepared from untreated oat flour. The serving of malted-oat porridge in the breakfast enhanced fractional $\mathrm{Fe}$ absorption by about $36 \%$, but the percentage absorption was still relatively low, i.e. $6 \% v .4 .4 \%$, or, if calculated in absolute amounts, $3.6 \mu \mathrm{mol}(0.20 \mathrm{mg})$ v. $2.7 \mu \mathrm{mol}(0.15 \mathrm{mg})$ absorbed Fe. A further improvement in $\mathrm{Fe}$ absorption may be possible by increasing the length of hydrolysis. Oat flour was soaked for only $7 \mathrm{~h}$ at $37.8^{\circ}$, resulting in a phytate reduction of about $77 \%$. Longer periods of soaking introduce a sourish taste in the malted-oat porridge. By further modification of the preparation of malted-oat porridge it might be possible to achieve lower phytate levels and, thus, increased Fe absorption (while maintaining an acceptable taste). The inhibitory effect of phytate has been found to be counteracted by ascorbic acid, and the relative effect of ascorbic acid was more marked the more the Fe absorption was inhibited by phytate (Hallberg et al. 1989). Thus, a feasible way to improve further the Fe absorption from the malted-oat porridge is to increase the ascorbic acid content of the meal.

The effect of phytate on non-haem-Fe absorption has been extensively investigated. Hallberg et al. (1989) concluded that the inhibition of non-haem-Fe absorption by phytates in human subjects is dose-dependent and that even a small amount of phytate causes marked inhibition. The greatest decrease in Fe absorption was found at the lowest levels, from 2 to $10 \mathrm{mg}(10-53 \mu \mathrm{mol})$ phytate-P. After the addition of $10-250 \mathrm{mg}(53-1344 \mu \mathrm{mol})$ phytate-P the rate of decrease in Fe absorption was lower but highly significant. In vitro studies of soaking, germination and the addition of phytase have shown that the phytate content of cereals should be reduced to very low levels to prevent a negative effect on Fe availability (Sandberg \& Svanberg, 1991; Svanberg et al. 1993). These results are also in agreement with recent human absorption studies (Brune et al. 1992).

Brune et al. (1992) measured Fe absorption from rye or wheat bread fermented in different ways, and having different phytate contents. The Fe absorption ratio from a bread with a phytate-P (sum of IP-3-IP-6) content of $203.5 \mathrm{mg}(1159 \mu \mathrm{mol})$ was $3.2 \%$, while serving a bread containing only $30.7 \mathrm{mg}$ (266 $\mu \mathrm{mol}$ ) phytate-P (sum of IP-3-IP-6) enhanced the absorption ratio to $9 \cdot 2 \%$. These values are in agreement with our observations.

Rossander et al. (1990) examined the effect of oat products on non-haem-Fe absorption in human subjects. Fe absorption was compared in continental-type breakfast meals consisting of wheat rolls, orange juice and coffee, and served with or without oat porridge. Except for the addition of milk to the meal, the composition was similar to that of the present study. In the study of Rossander et al. (1990) the phytate-P content of the breakfast containing porridge was $113 \mathrm{mg}(608 \mu \mathrm{mol})$. The serving of oat porridge reduced the fractional $\mathrm{Fe}$ absorption by about $60 \%$, from $12.4 \%$ to $5.2 \%$, in comparison with reference meals served without oat porridge. In our experiment the $\mathrm{Fe}$ absorption from oat porridge with a phytate-P (sum of IP-3-IP-6) content of $452 \mu \mathrm{mol}(83.6 \mathrm{mg}$ ) was $4.4 \%$ and the serving of malted-oat porridge containing $222 \mu \mathrm{mol}(35.5 \mathrm{mg}$ ) phytate-P (sum of IP3-IP-6) enhanced the Fe absorption ratio to $6 \%$. It is difficult however, to compare the results of Rossander et al. (1990) directly with those of the present study, since in our study the phytate content of the porridge was analysed using a method that separates the different inositol phosphates, whereas in the study of Rossander et al. (1990) the amounts of phytate, as determined by the Association of Official Analytical Chemists' method (Harland \& Oberleas, 1986), also includes partially dephosphorylated isomers of IP-6, and the contribution of these separate fractions to the total phytate-P content cannot be calculated.

The release of inorganic $P$ during soaking under optimal conditions for phytase activity has been used by several investigators in the assay of phytase activity (Bartnik \& Szafranska, 1987; Mayer \& Poljakoff-Mayber, 1989). In a previous study in our laboratory 
(Larsson \& Sandberg, 1995), using the same material as in the present study, we showed that the release of inorganic $P$ was related to the phytate reduction and that the release of $P$ was much higher in malted oats than in untreated oats. In the present study phytate degradation in malted oats was very low after 2 min of cooking in the microwave oven. Rapid absorption and thermal diffusion is achieved with microwaves (Buchta \& Svennebrink, 1993) owing to volumetric heating of the porridge, in contrast to surface heating, which might explain the rapid phytase inactivation (compared with conventional cooking). Studies in human subjects (Sandberg et al. 1987; Sandberg \& Andersson, 1988) and pigs (Sandberg et al. 1993) have demonstrated that the cereal phytase activity plays an important role in phytate degradation in the stomach and small intestine. We do not know whether intrinsic phytase activity in malted oats would increase phytate degradation during digestion, but it is possible that processing at lower temperature, keeping phytase active, might be favourable for the total absorption of minerals, in particular as optimal conditions for oat phytase occur at $37^{\circ}$ (Larsson \& Sandberg, 1992).

In conclusion, owing to the very high phytate content of oats, which inhibits not only the absorption of $\mathrm{Zn}$ but also the absorption of $\mathrm{Fe}$, it must be considered important to find a technological means to overcome this disadvantage. The results of our study indicate that larger amounts of $\mathrm{Fe}$ and $\mathrm{Zn}$ would be absorbed from oat products prepared from maltedoat flour than from the same products prepared from raw or commercial oats.

We would like to thank Ms Annette Almgren and Ms Elisabeth Gramatkovski for their excellent technical assistance. This work was supported by grants from the Cerealia Foundation R \& D, Stockholm, Sweden.

\section{REFERENCES}

Arvidsson, B., Cederblad, А̊, Björn-Rasmussen, E. \& Sandström, B. (1978). A radionuclide technique for studies of zinc absorption in man. International Journal of Nuclear Medicine and Biology 5, 104-109.

Bartnik, M. \& Szafranska, I. (1987). Changes in phytate content and phytase activity during the germination of some cereals. Journal of Cereal Science 5, 23-28.

Björn-Rasmussen, E., Hallberg, L. \& Isaksson, B. (1974). Food iron absorption in man. Application of the twopool extrinsic tag method to measure heme and non-heme iron absorption from the whole diet. Journal of Clinical Investigation 53, 247-255.

Brune, M., Rossander, L., Hallberg, L., Gleerup, A. \& Sandberg, A.-S. (1992). Iron absorption from bread in humans: inhibiting effects of cereal fiber, phytate and inositol phosphates with different numbers of phosphate groups. Journal of Nutrition 122, 442-449.

Buchta, R. \& Svennebrink, J. (1993). Using microwave energy for rapid heating of silicon wafers. In Microwave and High Frequency. Proceedings of the International Conference, Göteborg, Sweden, D5 [J. Kahl, editor]. Göteborg: SIK.

Cook, J. D., Layrisse, M., Martinez-Torres, C., Walker, R., Monsen, E. \& Finch, C. A. (1972). Food iron absorption measured by an extrinsic tag. Journal of Clinical Investigations 51, 805-815.

Eakins, J. D. \& Brown, D. A. (1966). An improved method for the simultaneous determination of iron-55 and iron-59 in blood by liquid scintillation counting. International Journal of Applied Radiation Isotopes 17, $391-397$.

Hallberg, L. (1980). Food iron absorption. In Methods in Hematology, pp. 116-133 [J. D. Cook, editor]. London: Churchill Livingstone.

Hallberg, L. \& Björn-Rasmussen, E. (1972). Determination of iron absorption from whole diet. A new two-pool model using two radioiron isotopes given as haem and non-haem iron. Scandinavian Journal of Haematology 9, 193-197.

Hallberg, L., Brune, M. \& Rossander, L. (1989). Iron absorption in man: ascorbic acid and dose-dependent inhibition by phytate. American Journal of Clinical Nutrition 49, 140-144.

Harland, B. F. \& Oberleas, D. (1986). An ion-exchange method for determination of phytate in foods: collaborative study. Journal of Association of Official Analytical Chemists 69, 667-670.

Kivistö, B., Cederblad, À., Davidsson, L., Sandberg, A.-S. \& Sandström, B. (1989). Effect of meal composition and phytate content on zinc absorption in humans from an extruded bran product. Journal of Cereal Science 10, $189-197$.

Larsson, M. \& Sandberg, A.-S. (1992). Phytate reduction in oats during malting. Journal of Food Science 57 , 994-997. 
Larsson, M. \& Sandberg, A.-S. (1995). Malting of oats in a pilot-plant process. Effects of heat treatment, storage and soaking conditions on phytate reduction. Journal of Cereal Science 21, 87-95.

Lönnerdal, B., Sandberg, A.-S., Sandström, B. \& Kunz, C. (1989). Inhibitory effects of phytic acid and other inositol phosphates on zinc absorption in suckling rats. Journal of Nutrition 119, 211-214.

Magnusson, B., Björn-Rasmussen, E., Hallberg, L. \& Rossander, L. (1981). Iron absorption in relation to iron status. Model proposed to express results of food iron absorption measurements. Scandinavian Journal of Haematology 27, 201-208.

Mayer, A. M. \& Poljakoff-Mayber, A. (1989). Dormancy, germination, inhibition and stimulation. In The Germination of Seeds, pp. 71-173, 4th ed. Oxford: Pergamon Press.

Nävert, B., Sandström, B. \& Cederblad, А. (1985). Reduction of phytate content of bran by leavening in bread and its effect on zinc absorption in man. British Journal of Nutrition 53, 47-53.

Rossander, L., Gleerup, A. \& Hallberg, L. (1990). Inhibitory effect of oat products on non-haem iron absorption in man. European Journal of Clinical Nutrition 44, 783-791.

Sandberg, A.-S. \& Adherinne, R. (1986). HPLC method for determination of inositol tri-, tetra-, penta-, and hexaphosphates in foods and intestinal contents. Journal of Food Science 51, 547-550.

Sandberg, A.-S. \& Andersson, H. (1988). Effect of dietary phytase on the digestion of phytate in the stomach and small intestine. Journal of Nutrition 118, 469-473.

Sandberg, A.-S., Andersson, H., Carisson, N.-G. \& Sandström, B. (1987). Degradation products of bran phytate formed during digestion in the human small intestine. Effect of extrusion cooking and digestibility. Journal of Nutrition 117, 2061-2065.

Sandberg, A.-S., Carlsson, N.-G. \& Svanberg, U. (1989). Effects of inositol tri-, tetra-, penta-, and hexaphosphates on in vitro estimation of iron availability. Journal of Food Science 54, 159-161.

Sandberg, A.-S., Larsen, T. \& Sandström, B. (1993). High dietary calcium levels decreases colonic phytate degradation in pigs fed a rapeseed diet. Journal of Nutrition 123, 559-566.

Sandberg, A.-S. \& Svanberg, U. (1991). Phytate hydrolysis by phytase in cereals, effects on in vitro estimation of iron availability. Journal of Food Science 56, 1330-1333.

Sandström, B. (1993). In Bioavailability '93, Nutritional, Chemical and Food Processing Implications of Nutrient Availability. Proceedings of the International Conference Bioavailability '93, Ettlingen, Federal Republic of Germany pp. 159-163 [U. Schlemmer, editor]. Karlsruhe: Bundesforschungsanstalt für Ernährung.

Sandström, B., Almgren, A., Kivistö, B. \& Cederblad. А. (1987). Zinc absorption in humans from meals based on rye, barley, oatmeal, triticale and whole-wheat. Journal of Nutrition 117, 1898-1902.

Sandström, B. \& Sandberg, A.-S. (1992). Inhibitory effects of isolated inositol phosphates on zinc absorption in humans. Journal of Trace Elements and Electrolytes in Health and Disease 6, 99-103.

Svanberg, U., Lorri, W. \& Sandberg, A.-S. (1993). Lactic fermentation of non-tannin and high-tannin cereals: Effects on in vitro estimation or iron availability and phytate hydrolysis. Journal of Food Science 58, 408-412.

Turnlund, J. R., King, J. C., Keyes, W. R., Gong, B. \& Michel, M. C. (1984). A stable isotope study of zinc absorption in young men: effects of phytate and alfa-cellulose. American Journal of Clinical Nutrition 40, $1071-1077$. 